\title{
Impact of traumatic events incurred by asylum-seekers on mental health and utilization of medical services
}

\author{
Maya Siman-Tov ${ }^{1}$, Moran Bodas ${ }^{1,2}$, Alex Wang $^{3}$, Michael Alkan ${ }^{3}$ and Bruria Adini ${ }^{1 *}$ (D)
}

\begin{abstract}
Background: Asylum-seekers from Africa immigrate to Israel through the Sinai desert and are often exposed to traumatic events.

Objective: To identify the scope and types of medical services required by asylum-seekers and the relationship between delayed medical care to development of post-traumatic stress disorder (PTSD) and overutilization of medical services.

Methods: Asylum-seekers that entered Israel between 2009 and 2012 who utilized the Open Clinic of Physicians for Human Rights were interviewed to record their experiences in the Sinai, and document the traumatic events they were exposed to, their medical diagnoses, and clinic visits. Linkages between diagnoses to exposure to traumatic events and period of time until presentation to the clinic were investigated.

Results: Male vs female asylum-seekers visited the clinic more times (24\% vs 15\% respectively, utilized $>5$ visits). Higher ransom and longer periods in Sinai correlated with higher number of clinic visits and PTSD. Asylum-seekers with PTSD versus other medical complaints approached the clinic more times ( $\geq 5$ visits). Asylum-seekers that approached the clinic closer to their arrival time (up to 18 months from arrival) versus a later period ( $>18$ months) presented a significantly lower prevalence of PTSD (3.4 and 40.5\% respectively; $p<0.001$ ) and lower utilization of clinic's services $(p<0.001)$.

Conclusions: PTSD among asylum-seekers appears to be associated more with length of exposure to stressful events than number/types of traumatic events and with delay in receiving medical care. Improving access to medical care may reduce asylum-seekers' development of PTSD and lead to lower utilization of services.
\end{abstract}

Keywords: Asylum-seekers, Traumatic events, Torture, Utilization of medical services, Post-traumatic stress disorder

\section{Background}

Displaced populations including asylum-seekers and refugees were recognized as a global challenge since WWII but have been highlighted as a world-wide concern in the past decade $[1,2]$. Today there are over 70.8 million forcibly displaced people worldwide that are recognized by the United Nations High Commissioner for Refugees [3].

Over 60,000 asylum-seekers entered Israel between the years 2006 to 2012, primarily from African countries

\footnotetext{
*Correspondence: adini@tauex.tau.ac.il; adini@netvision.net.il

${ }^{1}$ Emergency management \& disaster medicine department, School of Public Health, Sackler Faculty of Medicine, Tel Aviv University, Tel Aviv, Israel Full list of author information is available at the end of the article
}

such as Sudan and Eritrea [4, 5]. The number of asylumseekers significantly dropped after 2012 as a barrier fence between Israel and the Sinai desert was constructed, substantially limiting their ability to cross the border [5, 6]. As of 2017, less than 36,000 asylum seekers remained in Israel [4]. These individuals are often regarded by authorities as undocumented migrant workers or "infiltrators" that are not entitled to the benefits, including medical services, that are legally provided to refugees $[4,6]$.

Asylum seekers that entered Israel through the Sinai desert were often exposed to extremely stressful events, including violence, torture, and captivity [5, 7]. Many of them were exposed to gender-based violence and human

(c) The Author(s). 2019 Open Access This article is distributed under the terms of the Creative Commons Attribution 4.0 International License (http://creativecommons.org/licenses/by/4.0/), which permits unrestricted use, distribution, and 
trafficking $[8,9]$. Traumatic events among migrants and asylum-seekers have been identified as triggers for the development of both physical and mental health problems, specifically Post-Traumatic Stress Disorder (PTSD), depression and anxiety [10-13].

Marginalized populations including asylum-seekers have relatively limited access to essential medical services and difficulty integrating into healthcare systems. These populations often suffer from psychiatric conditions, which have widely been associated with increased utilization of medical services, and may result in the host countries' perception that their ability to provide medical services to the asylum-seekers exceeds their capacity $[1$, 10, 14]. These barriers of asylum-seekers to care may stem from fear of deportation, detainment in camps lacking in basic healthcare facilities, culture-specific barriers, ineligibility to obtain care in public services, or lack of funding to be treated in the private sector $[1,15]$.

The volunteer-based "Open Clinic" in Tel Aviv run by Physicians for Human Rights Israel (PHR) [16-18] has provided care to the marginalized and uninsured for over 20 years and has been one of the primary clinics providing health-services for the asylum seekers in Israel $[17,19]$. The clinic is set within the metropolitan area and serves the asylum-seekers that reside in the urban setting. In 2012, 1150 asylum seekers were interviewed about their experiences regarding their stay in the Sinai desert. These traumatic experiences in combination with the difficulties of cultural acclimation contributed largely to depression and mental illness $[7,18]$. The open clinic employs senior physicians that though are not specialists in psychiatry, are highly experienced and have been trained in diagnosing mental health symptomatology. Upon such diagnoses, the patients, including those suffering from Post Trauma Stress Disorder (PTSD) were immediately referred to treatment in a designated clinic ran by the Ministry of Health. This was deemed as important, especially considering the uncertainty of the asylum-seekers' situation and their fear of the future.

As the government of Israel has not made any final decisions regarding the patriation of the asylum seekers, their legal and thus medical status remain unresolved for the last decade [19]. This may be reflected in an increase of patients seen at the clinic since 2015 who had not before used the services of the clinic. The clinical observation of a high frequency of PTSD symptoms, long after the traumatic events, hinted that this group may be different, and more information is needed to elucidate this difference.

\section{Importance}

Provision of universal health coverage is a core element of the Sustainable Development Goals [2]. Ensuring the capacity of host countries to provide essential medical care to asylum-seekers is dependent on tailoring the services to their specific medical needs [1, 15]. Identifying factors that aggravate medical needs and designing measures that may decrease the development of health problems, will contribute to cost-benefit, effective healthcare provision. Therefore, there is a need to understand the impact of traumatic events on the utilization of medical services $[12,14]$.

\section{Goals of this investigation}

To identify the scope and types of medical services utilized by asylum-seekers and the relationship between delayed medical care to the development of PTSD.

\section{Methods}

A retrospective cohort study of 861 asylum-seekers who entered Israel between 2009 and 2012 and received medical care at the Open Clinic of Physicians for Human Rights was performed. The asylum-seekers that approach the clinic are those that do not have medical insurance or eligibility to medical coverage, and thus they seek medical services at the clinic. Following the request of the UNHCR (the United Nations High Commissioner of Refugees) to document traumatic events that asylumseekers were exposed to during their flee to places of refuge, all patients that presented to the clinic up to 2012 were screened by the clinic's staff via a brief questionnaire about their experiences in the Sinai desert. They were asked about length of stay in Sinai, deprivation of vital elements (lack of food, water, shelter, medical care etc.), exposure to torture of themselves or of others (beating, kidnapping, ransom etc.), and sum of ransom (if paid). Those who screened positive (i.e. were exposed to any type of torture), were interviewed at length in their native languages of Tigrinya or Arabic. Patients who were not exposed to any traumatic event during their stay in the Sinai desert were excluded from the study. The asylum-seekers were further diagnosed and treated by the clinic's physicians. Asylum-seekers that presented from 2012 to 2016 were similarly screened through interviews by the physicians at the clinic, using language interpreters. Data from the interviews and from chart reviews were collected and anonymized.

The research protocol was approved by the ethics committees of the Ben-Gurion University of the Negev number 20164 from February 2, 2016. Following this approval, the retrospective study was initiated, based on the files of the asylum-seekers that are kept in the clinic.

Data collected included demographic characteristics, types of traumatic experiences in the Sinai desert, and clinical information including date of presentation at the 
Table 1 Demographic, experiences in Sinai desert and clinic characteristics of the asylum-seekers

\begin{tabular}{ll}
\hline & $N=861$ \\
\hline Male N (\%) & $542(63.2 \%)$ \\
Unknown- 3 & \\
Age (years) mean \pm SD & $29.03 \pm 7.71$ \\
$<20$ & $60(7.0 \%)$ \\
$21-30$ & $517(60.1 \%)$ \\
$31-40$ & $213(24.8 \%)$ \\
$41+$ & $70(8.1 \%)$ \\
Unknown- 1 & \\
(Origin) country of origin N (\%) & \\
Eritrea & $724(84.3 \%)$ \\
Sudan & $102(11.9 \%)$ \\
Other & $33(3.8 \%)$ \\
Unknown- 2 & \\
Number of days spent in the Sinai desert & $11[5-30],(0-520)^{\mathrm{a}}$ \\
$<6$ & $234(30.0 \%)$ \\
$7-20$ & $264(33.8 \%)$ \\
$21-60$ & $178(22.8 \%)$ \\
$61+$ & $105(13.4 \%)$ \\
Unknown- &
\end{tabular}

Unknown- 80

Amounts of ransom (US\$)

Limited amount $(<2500)$

Intermediate amount (2500-4000)

High amount (> 4000)

Unknown- 134

Type of torture

$\begin{array}{ll}\text { Gunshot wounds Unknown- } 285 & 224(38.9 \%) \\ \text { Physical assault Unknown- } 123 & 307(41.6 \%) \\ \text { Sexual assault Unknown- } 265 & 39(6.5 \%) \\ \text { Other mistreatment Unknown- } 257 & 64(10.6) \\ \text { Imprisonment Unknown- } 194 & 604(90.6 \%) \\ \text { Modified Harvard Trauma Score } & \\ \text { Low } & 499(58.0 \%) \\ \text { Moderate } & 279(32.4 \%) \\ \text { High } & 83(9.6 \%)\end{array}$

Time till arrival to clinic

$<6$ months

6-18 months

$>18$ months

Diagnosis

Pregnancy

STD + Gynecology

Skin

Gastrointestinal
206 (27.4\%)

267 (35.5\%)

279 (37.1\%)

3000 [2500-3400], $(0-43,500)^{\mathrm{a}}$

265 (36.5\%)

352 (48.5\%)

$109(15.0 \%)$

$83(9.6 \%)$

$203(23.6 \%)$

$61(7.1 \%)$

$53(6.2 \%)$

$93(10.8 \%)$
Table 1 Demographic, experiences in Sinai desert and clinic characteristics of the asylum-seekers (Continued)

\begin{tabular}{ll}
\hline & $N=861$ \\
\hline Trauma & $93(10.8 \%)$ \\
Post Traumatic Syndrome Disorder & $134(15.6 \%)$ \\
Orthopedic- non-trauma & $83(9.6 \%)$ \\
Respiratory & $86(10.0 \%)$ \\
Eye & $33(3.8 \%)$ \\
Liver, diabetes, Blood pressure, Tuberculosis & $22(2.6 \%)$ \\
Number of clinic visits & \\
1 & $295(42.3 \%)$ \\
$2-4$ & $260(37.2 \%)$ \\
$5+$ & $143(20.5 \%)$ \\
Unknown- 163 & \\
\hline $\begin{array}{l}\text { aData is presented as mean } \pm \text { standard deviation, N(\%), median [p25-p75] } \\
\text { and (Minimum-Maximum) }\end{array}$
\end{tabular}

clinic, diagnoses, number of visits to the clinic, and medical services that were utilized, as follows:

\section{Demographic characteristics}

Gender, age ( $<20$ years old, $21-30$ years old, $31-40$ years old and $41+$ years old), country of origin and date of arrival to Israel.

\section{Experiences in Sinai desert}

Number of days spent in the Sinai desert ( $<7$ days, $7-20$ days, 21-60 days, $>60$ days), ransom paid in order to be released after kidnap $(<2500$ USD [limited], 2500-4000 USD [intermediate] and $>4000$ USD [high]), type of traumatic event (gunshot wounding, physical assault, sexual assault, imprisonment, or other mistreatment).

The modified Harvard Trauma Questionnaire (MHTQ) has been extensively used in the past 25 years to characterize exposures to traumatic events, particularly in migrant asylum-seeker and refugee populations, which include abduction, imprisonment, physical and sexual violence among others $[10,11]$. Consequently, these events have been identified as triggers for the development of both physical and mental health problems, specifically PTSD and functional distress in this population [12, 13]. The MHTQ is also used to diagnose symptoms of PTSD and functional distress in these populations $[12,13]$.

Based on this data, the modified Harvard Trauma Score (MHTS) was calculated to the asylum seekers and categorized into three categories from 'Low' (0-1 type of torture), 'Moderate' ( 2 types) and 'High' (3-5 types).

\section{Clinical data}

Per chart review, medical diagnoses were categorized into the following categories: pregnancy, sexual 
transmitted disease and gynecology, skin, gastrointestinal, physical trauma, PTSD, orthopedic non-trauma, respiratory, ocular and internal diseases including liver, diabetes, hypertension, and tuberculosis. The category of orthopedic non-trauma includes chronic conditions that did not involve a recent injury, such as pain stemming from old injuries. Utilization of the clinic was separately categorized based on number of visits (1 visit, $2-4$ visits, and 5+ visits). A diagnosis of PTSD was made in patients who presented with three or more of the criteria of the Diagnostic and Statistical Manual of Mental Disorder - 5 (DSM-5) $[12,20]$. The DSM-5 recognizes that PTSD is derived from experience or threat of traumatic events, including torture, injuries, sexual assaults or other violent behavior. The actual exposure of the individual to such events and/or witnessing them and/or exposure of loved ones to such atrocities, may cause clinical stress and incapacity of the individual to function properly [20]. The open clinic's physicians are the ones that diagnosed PTSD among the asylum-seekers, dependent on DSM-5 [12, 20].

\section{Data analysis}

Descriptive statistics were used to analyze the characteristics of the sample. Linkages between diagnoses to exposure to stressful events and period of time until presentation to the clinic, number of visits to the clinic and different diagnoses were investigated using chi square test. All statistical analyses were performed using SPSS software version 25. P-values lower than 0.05 were considered to be statistically significant.

\section{Results}

Table 1 presents the demographic characteristics, traumatic experiences in the Sinai desert, clinical data and the calculated MHTQ. The majority of patients were male (63\%), under 30 (67\%), and from Eritrea (84\%). About $64 \%$ stayed in the Sinai desert up to 20 days. Almost $64 \%$ paid significant amounts for ransom.

\section{Visits to the clinic}

Utilization of the clinic was plotted against demographic characteristics, experiences in the Sinai desert and diagnoses, presented in Fig. 1 and Table 2. Males presented more times ( $\geq 5$ visits) than females (24\% vs $15 \%$, respectively, $p=.037)$. Those who paid the highest ransom and/or spent more than 2 months in the Sinai desert presented more frequently to the clinic. Patients with non-traumatic orthopedic complaints (43\%) and PTSD (35\%) presented at the clinic more times ( $\geq 5$ visits) than those with other medical complaints (Table 2).

Logistic regression model was used to assess the factors associated with a higher number of clinic visits $(\geq 5)$

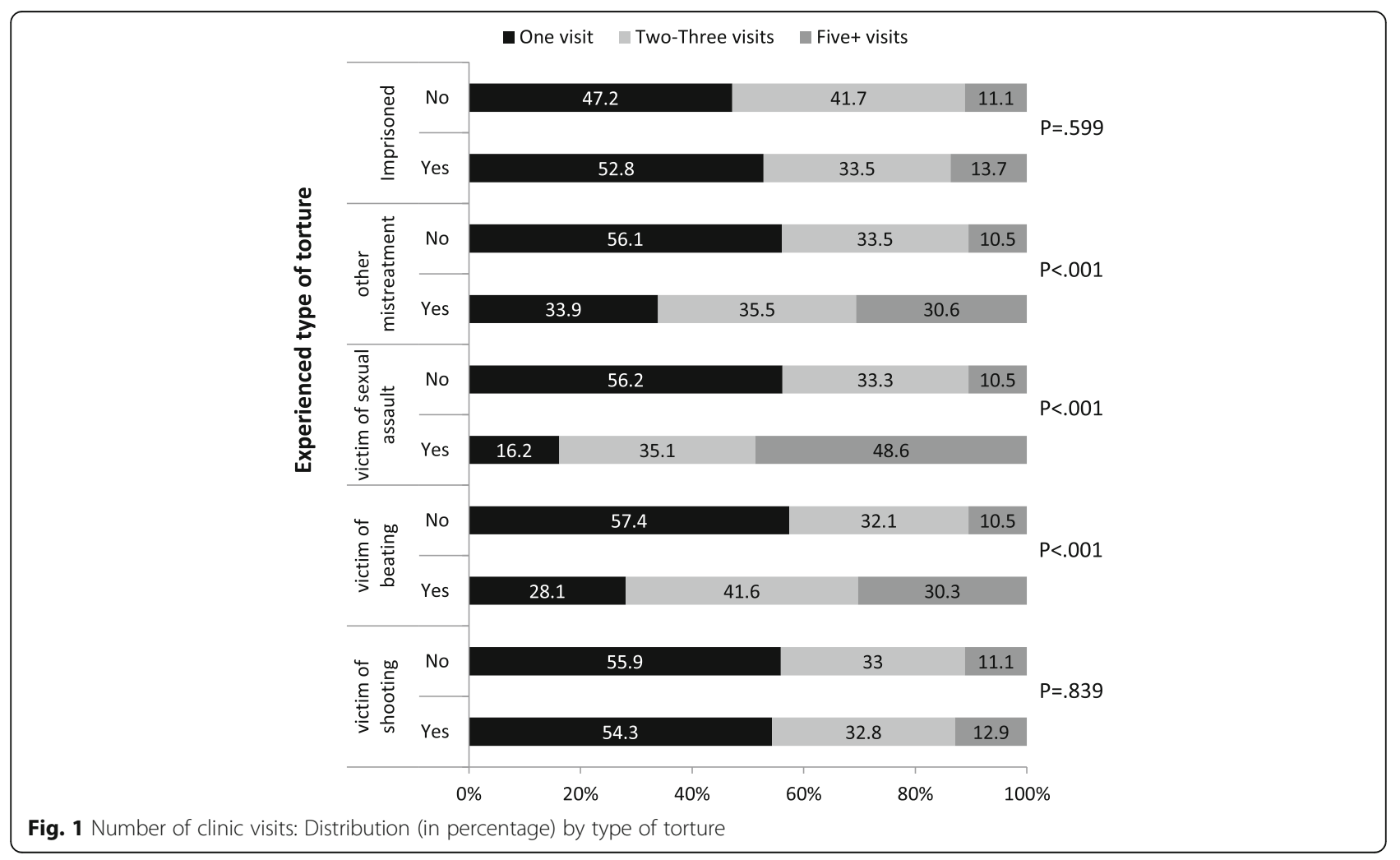


Table 2 Number of clinic visits by demographic, experiences in Sinai desert and diagnosis

\begin{tabular}{|c|c|c|c|c|c|}
\hline & \multicolumn{5}{|c|}{ Number of clinic visits } \\
\hline & 1 & $2-4$ & $5+$ & $x^{2}$ & $P$-value \\
\hline \multicolumn{6}{|l|}{ Gender } \\
\hline Male & $41.1 \%$ & $35.4 \%$ & $23.5 \%$ & \multirow[t]{2}{*}{6.60} & \multirow[t]{2}{*}{.037} \\
\hline Female & $44.5 \%$ & $40.2 \%$ & $15.4 \%$ & & \\
\hline \multicolumn{6}{|l|}{ Age (Years) } \\
\hline$<20$ & $52.3 \%$ & $40.9 \%$ & $6.8 \%$ & \multirow[t]{4}{*}{25.71} & \multirow[t]{4}{*}{$<.001$} \\
\hline $21-30$ & $44.8 \%$ & $38.9 \%$ & $16.4 \%$ & & \\
\hline $31-40$ & $37.9 \%$ & $32.2 \%$ & $29.9 \%$ & & \\
\hline $41+$ & $29.1 \%$ & $38.2 \%$ & $32.7 \%$ & & \\
\hline \multicolumn{6}{|l|}{ Country of origin } \\
\hline Eritrea & $42.5 \%$ & $38.1 \%$ & $19.4 \%$ & \multirow[t]{3}{*}{6.41} & \multirow[t]{3}{*}{.171} \\
\hline Sudan & $44.4 \%$ & $29.6 \%$ & $25.9 \%$ & & \\
\hline Other & $22.2 \%$ & $44.4 \%$ & $33.3 \%$ & & \\
\hline \multicolumn{6}{|l|}{ Days spent in the Sinai desert } \\
\hline$<6$ & $54.4 \%$ & $34.5 \%$ & $11.1 \%$ & \multirow[t]{4}{*}{39.50} & \multirow[t]{4}{*}{$<.001$} \\
\hline $7-20$ & $51.8 \%$ & $36.7 \%$ & $11.6 \%$ & & \\
\hline $21-60$ & $40.4 \%$ & $37.7 \%$ & $21.9 \%$ & & \\
\hline $61+$ & $23.8 \%$ & $44.6 \%$ & $31.7 \%$ & & \\
\hline \multicolumn{6}{|l|}{ Amounts of ransom (\$US) } \\
\hline Limited amount $(<2500)$ & $52.1 \%$ & $33.5 \%$ & $14.4 \%$ & \multirow[t]{3}{*}{14.80} & \multirow[t]{3}{*}{.005} \\
\hline Intermediate amount (2500-4000) & $49.8 \%$ & $38.2 \%$ & $12.0 \%$ & & \\
\hline High amount (> 4000) & $36.1 \%$ & $37.1 \%$ & $26.8 \%$ & & \\
\hline \multicolumn{6}{|l|}{ Modified Harvard Trauma Score } \\
\hline Low & $41.5 \%$ & $38.4 \%$ & $20.1 \%$ & \multirow[t]{3}{*}{1.55} & \multirow[t]{3}{*}{.818} \\
\hline Moderate & $41.9 \%$ & $36.0 \%$ & $22.0 \%$ & & \\
\hline High & $47.8 \%$ & $34.8 \%$ & $17.4 \%$ & & \\
\hline \multicolumn{6}{|l|}{ Time till arrival to clinic } \\
\hline$<6$ months & $52.8 \%$ & $32.0 \%$ & $15.2 \%$ & \multirow[t]{3}{*}{65.96} & \multirow[t]{3}{*}{$<.001$} \\
\hline 6-18 months & $53.7 \%$ & $35.8 \%$ & $10.6 \%$ & & \\
\hline$>18$ months & $24.8 \%$ & 41.75 & $33.5 \%$ & & \\
\hline \multicolumn{6}{|l|}{ Diagnosis } \\
\hline Pregnancy & $50.6 \%$ & $45.5 \%$ & $3.9 \%$ & \multirow[t]{10}{*}{117.35} & \multirow[t]{10}{*}{$<.001$} \\
\hline STD / Gynecology & $49.0 \%$ & $29.4 \%$ & $21.6 \%$ & & \\
\hline Skin & $61.0 \%$ & $22.0 \%$ & $17.1 \%$ & & \\
\hline Gastrointestinal & $51.5 \%$ & $35.3 \%$ & $13.2 \%$ & & \\
\hline Trauma & $48.1 \%$ & $23.4 \%$ & $28.6 \%$ & & \\
\hline Post Traumatic Syndrome Disorder & $16.9 \%$ & $48.5 \%$ & $34.6 \%$ & & \\
\hline Orthopedic- non-trauma & $24.7 \%$ & $32.5 \%$ & $42.8 \%$ & & \\
\hline Respiratory & $49.2 \%$ & $42.4 \%$ & $8.5 \%$ & & \\
\hline Eye & $62.5 \%$ & $29.2 \%$ & $8.3 \%$ & & \\
\hline Liver, diabetes, Blood pressure, Tuberculosis & $58.8 \%$ & $23.5 \%$ & $17.6 \%$ & & \\
\hline
\end{tabular}


compared to less than 5 visits. The variables entered to the model were demographics and experiences in the Sinai desert. The models suggested that only older asylum-seekers and longer stays in the Sinai desert $(>20$ days) predict a higher utilization of health services, as reflected in the number of clinic visits (Table 3).

Asylum-seekers that were exposed to physical violence, sexual assault or other mistreatment, presented to the clinic more times ( $\geq 5$ visits) compared with those who were not afflicted with such traumatic events (Fig. 1).

Asylum-seekers that sought care at a later date in relation to their arrival time to Israel (>18 months) presented to the clinic more ( $\geq 5$ visits) compared to those

Table 3 Logistic regressions identifying variables associated with 5 or more clinic visits by demographic and experiences in Sinai desert

\begin{tabular}{|c|c|c|}
\hline & OR $95 \% \mathrm{Cl}$ & $P$-value \\
\hline \multicolumn{3}{|l|}{ Gender } \\
\hline Male & $1.12(0.61-2.05)$ & .714 \\
\hline Female & 1 & \\
\hline \multicolumn{3}{|l|}{ Age (Years) } \\
\hline$<20$ & 1 & \\
\hline $21-30$ & $5.56(0.72-42.80)$ & .100 \\
\hline $31-40$ & $10.25(1.27-82.49)$ & .029 \\
\hline $41+$ & $13.09(1.41-121.41)$ & .024 \\
\hline \multicolumn{3}{|l|}{ Country of origin } \\
\hline Eritrea & $0.37(0.08-1.66)$ & .196 \\
\hline Sudan & $0.61(0.11-3.34)$ & .567 \\
\hline Other & 1 & \\
\hline \multicolumn{3}{|l|}{ Days spent in the Sinai desert } \\
\hline$<6$ & 1 & \\
\hline $7-20$ & $1.31(0.62-2.76)$ & .478 \\
\hline $21-60$ & $2.36(1.05-5.31)$ & .039 \\
\hline $61+$ & $4.11(1.45-11.68)$ & .008 \\
\hline \multicolumn{3}{|l|}{ Amounts of ransom (\$US) } \\
\hline Limited amount $(<2500)$ & 1 & \\
\hline Intermediate amount (2500-4000) & $1.47(0.60-3.59)$ & .400 \\
\hline High amount (>4000) & $0.85(0.44-1.64)$ & .619 \\
\hline \multicolumn{3}{|l|}{ Modified Harvard Trauma Score } \\
\hline Low & 1 & \\
\hline Moderate & $0.67(0.37-1.21)$ & .181 \\
\hline High & $0.63(0.25-1.54)$ & .307 \\
\hline \multicolumn{3}{|l|}{ Time till arrival to clinic } \\
\hline$<6$ months & 1 & \\
\hline 6-18 months & $0.79(0.42-1.50)$ & .467 \\
\hline$>18$ months & $1.05(0.50-2.21)$ & .897 \\
\hline
\end{tabular}

that sought care within the first 18 months from arrival) (34, and $11 \%$, respectively; $p<0.001$ ). (Table 2 ).

\section{Post-traumatic stress disorder}

The incidence of PTSD according to demographic characteristics, experiences in the Sinai desert and utilization of medical services in the clinic is presented in Table 4. PTSD was found to be more prevalent among men versus women ( $21 \%$ vs. $6 \%$ respectively, $p<0.001)$, as well as among older (ages $\geq 31$ ) compared to younger $(<20)$ patients $(40 \%$ vs. $18 \%$ respectively $p=.005)$. A longer period spent in the Sinai desert correlated with the diagnosis of PTSD more frequently (44\% for $61+$ days vs $2 \%$ for less than 7 days, $p<0.001$ ). A higher amount of ransom paid while in the Sinai desert correlated with PTSD (31\% for high amounts, vs $2 \%$ for a limited amount, $p<$ $0.001)$.

Although no association was found between PTSD and MHTS directly, examination of separate types of abuse, except for imprisonment, correlated with a diagnosis of PTSD (Fig. 2).

Asylum-seekers that sought care earlier presented with a significantly lower prevalence of PTSD (3.4\% within the first 6 months, $2.2 \%$ within the first 18 months and $40.5 \%$ after 18 months, $p<0.001)$. They also presented lower prevalence of non-trauma orthopedic complaints (4.9, 4.5 and $19.4 \%$, respectively; $p<0.001$ ) but a significantly higher prevalence of pregnancies $(28.2,37.1$ and $7.9 \%$ respectively; $p<0.001)$.

A logistic regression model was used to assess factors associated with PTSD. The variables entered to the model were demographic, experiences in the Sinai desert and clinic visits. The model suggested that gender (male OR 5.42 95\% CI 2.07-14.20), a higher amount of ransom (moderate OR 12.71 95\% CI 2.71-59.57 and high OR $6.0095 \%$ CI 1.57-22.86), a higher number of clinic visits (2-4 visits OR 6.09 95\% CI 2.23-16.64 and $\geq 5$ visits OR $3.3295 \%$ CI 1.08-10.25) and delay in presentation to the clinic (OR 7.79 95\% CI 2.41-25.23) predict PTSD. (Table 4) (Fig. 2).

\section{Discussion}

Limited access to healthcare services and development of varied mental health symptomatology have been identified as characteristic of displaced populations [21-23]. Individuals with witnessed traumatic events frequently display mental health disorders $[24,25]$. Similar to previous studies, the current study suggests that the combination of torture in the context of acculturation may result in increased signs of mental illness [10-12].

Contrary to numerous prior studies that suggest a higher prevalence of PTSD among women [13, 23, 26], the current study identifies a higher prevalence among men. This may be derived from a greater 
Table 4 PTSD distribution by demographic, experiences in Sinai desert and clinic characteristics and results of logistic regressions identifying variables associated with PTSD

\begin{tabular}{|c|c|c|c|c|c|}
\hline \multirow{3}{*}{$\overline{G e n d e r}$} & \multicolumn{4}{|c|}{ PTSD diagnosis } & \multirow{2}{*}{$\begin{array}{l}\text { OR }(95 \% \mathrm{Cl}) \\
\text { for PTSD }\end{array}$} \\
\hline & \multirow[t]{2}{*}{ Yes } & \multirow[t]{2}{*}{ No } & \multirow[t]{2}{*}{$x^{2}$} & \multirow[t]{2}{*}{$P$-value } & \\
\hline & & & & & \\
\hline & $21.2 \%$ & $78.8 \%$ & 35.02 & $<.001$ & $5.42(2.07-14.20)^{* *}$ \\
\hline Female & $6.0 \%$ & $94.0 \%$ & & & 1 \\
\hline \multicolumn{6}{|l|}{ Age (Years) } \\
\hline$<20$ & $3.3 \%$ & $96.7 \%$ & 12.93 & .005 & 1 \\
\hline $21-30$ & $14.3 \%$ & $85.7 \%$ & & & $0.92(0.16-5.21)$ \\
\hline $31-40$ & $21.1 \%$ & $78.9 \%$ & & & $1.09(0.17-7.95)$ \\
\hline $41+$ & $18.6 \%$ & $81.4 \%$ & & & $0.21(0.02-2.07)$ \\
\hline \multicolumn{6}{|l|}{ Country of origin } \\
\hline Eritrea & $16.3 \%$ & $83.7 \%$ & 1.71 & .425 & $1.93(0.20-18.35)$ \\
\hline Sudan & $11.8 \%$ & $88.2 \%$ & & & $2.96(0.21-42.09)$ \\
\hline Other & $12.1 \%$ & $87.9 \%$ & & & 1 \\
\hline \multicolumn{6}{|l|}{ Days spent in the Sinai desert } \\
\hline$<6$ & $1.7 \%$ & $98.3 \%$ & 152.03 & $<.001$ & 1 \\
\hline $7-20$ & $3.4 \%$ & $96.6 \%$ & & & $1.23(0.28-5.45)$ \\
\hline $21-60$ & $19.7 \%$ & $80.3 \%$ & & & $3.47(0.81-14.81)$ \\
\hline $61+$ & $43.8 \%$ & $56.2 \%$ & & & $2.75(0.51-14.90)$ \\
\hline \multicolumn{6}{|l|}{ Amounts of ransom (US\$) } \\
\hline Limited amount $(<2500)$ & $1.9 \%$ & $98.1 \%$ & 85.01 & $<.001$ & 1 \\
\hline Intermediate amount (2500-4000) & $7.1 \%$ & $92.9 \%$ & & & $12.71(2.71-59.57)^{* *}$ \\
\hline High amount (> 4000) & $31.2 \%$ & $68.8 \%$ & & & $6.00(1.57-22.86)^{* *}$ \\
\hline \multicolumn{6}{|l|}{ Modified Harvard Trauma Score } \\
\hline Low & $15.6 \%$ & $84.4 \%$ & 4.06 & .131 & 1 \\
\hline Moderate & $17.6 \%$ & $82.4 \%$ & & & $0.76(0.32-1.81)$ \\
\hline High & $8.4 \%$ & $91.6 \%$ & & & $0.78(0.21-2.90)$ \\
\hline \multicolumn{6}{|l|}{ Time till arrival to clinic } \\
\hline$<6$ months & $3.4 \%$ & $96.6 \%$ & 179.49 & $<.001$ & 1 \\
\hline $6-18$ months & $2.2 \%$ & $97.8 \%$ & & & $0.50(0.13-1.95)$ \\
\hline$>18$ months & $40.5 \%$ & $59.5 \%$ & & & $7.79(2.41-25.23)^{* *}$ \\
\hline \multicolumn{6}{|l|}{ Number of clinic visits } \\
\hline 1 & $7.5 \%$ & $92.5 \%$ & 45.23 & $<.001$ & 1 \\
\hline $2-4$ & $24.2 \%$ & $75.8 \%$ & & & $6.09(2.23-16.64)^{* * *}$ \\
\hline $5+$ & $31.5 \%$ & $68.5 \%$ & & & $3.32(1.08-10.25)^{*}$ \\
\hline
\end{tabular}

${ }^{*} p<.05{ }^{* *} p<.01{ }^{* * *} p<.001$

perceived risk of being detained and deported, which under the current sociopolitical climate and passage of the Israeli "Anti-Infiltration" law, has allowed for the construction of several detention facilities that only accommodate male asylum seekers [5]. It may also result from the expectation of men to be primary providers, so that the inability to appropriately function in this role may aggravate their mental health. It should though be noted that not only the traumatic events themselves, but also the harsh life encountered by the asylum-seekers in their origin countries, their current financial loss and diminished hope for the future, may likewise contribute to significant psychologic damage.

It was surprising that PTSD among asylum-seekers appears to be associated more with the overall length of exposure to stressful events rather than the actual number of traumatic episodes. Several studies presented 


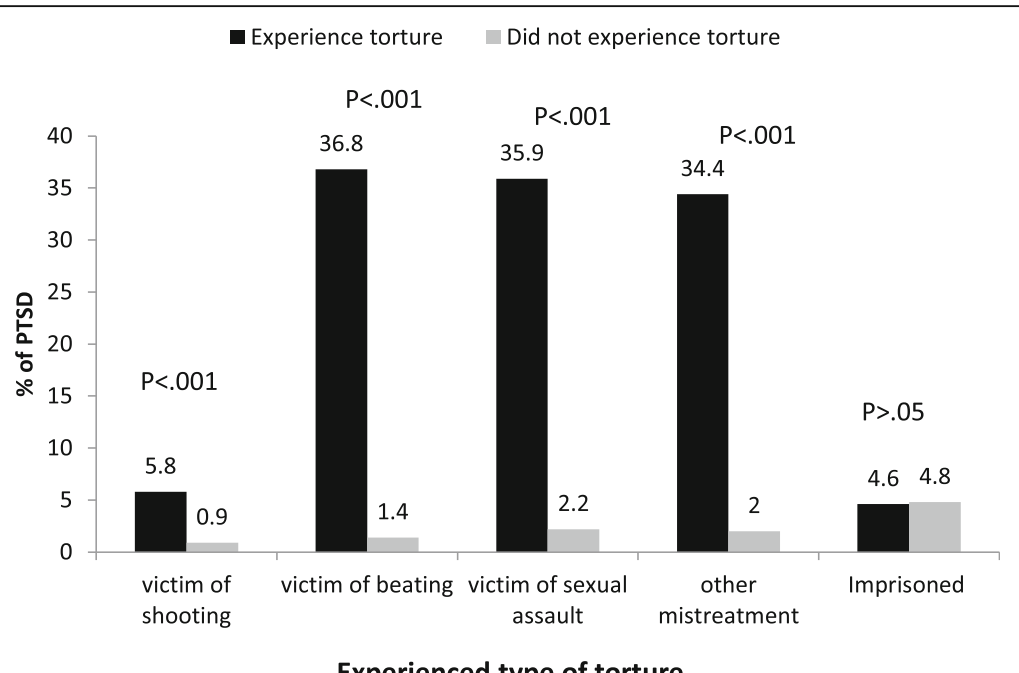

Experienced type of torture

Fig. 2 PTSD distribution (in percentage) by type of torture

that the severity and number of traumatic events encountered by the asylum seekers are related to the development of PTSD $[10,11,15]$. The current study proposes that exposure to even one type of stressful traumatic event is sufficient to contribute to the onset of PTSD. These findings strengthen the idea that despite the number of traumatic stressors, individuals exposed to protracted periods of displacement may have increased PTSD and mental health problems [5, 23].

Similarly, the need to pay higher ransoms in order to be released from captivity was found to be related with higher levels of PTSD. Demands for ransom are a common practice in areas of conflict around the globe [26, 27]. As displaced populations often do not have strong support systems that they can approach to pay the required ransom, this demand presents a highly stressful traumatic event. Social support has been found to be a protective factor against development of PTSD, even in cases of exposure to traumatic events [5]. The lack of these support systems most probably contributes to an enhanced vulnerability of this population.

Patients with delayed medical care had a higher utilization of healthcare services over time. This suggests that any perceived or actual barrier to care ultimately increases a society's healthcare burden. Given the current context where numerous countries have developed increasingly restrictive policies concerning access to healthcare for displaced populations, this may have a detrimental impact financially [27-30]. Given the increasing global burden of displaced populations around the world, the need for improved accessibility must be highlighted. Enhancing access to medical services may significantly decrease the development of PTSD among asylum-seekers and ultimately less resources will be required to treat this population [15].

The study has several limitations. The lack of information concerning asylum seekers who did not present to the PHR clinic seeking medical care may be confounding. In addition, this study retrospectively compares groups of patients who are demographically similar, but were assessed by different medical providers.

To conclude, it is vital to understand risk and protective factors of asylum-seekers in relation to access to medical care, to tailor the medical treatment to their needs and ease their acclimatization in the receiving country. Consequently, it may be possible to reduce their vulnerability and development of PTSD and achieve a more efficient utilization of healthcare resources. Implementing outreach measures that integrate vulnerable populations into the healthcare and social framework earlier would be expected to alleviate suffering and achieve a more successful absorption of displaced populations in societies world-wide.

\section{Abbreviations}

DSM-5: Diagnostic and Statistical Manual of Mental Disorders 5; MHTQ: modified Harvard Trauma Questionnaire; MHTS: modified Harvard Trauma Score; PHR: Physicians for Human Rights; PTSD: Post Traumatic Stress Disorder; UNHCR: United Nations High Commissioner of Refugees

\section{Acknowledgements}

The authors wish to thank the volunteers and employees of the Open Clinic of Physicians for Human Rights that assisted in gathering the data.

\section{Authors' contributions}

MA and BA conceived the study, supervised the conduct of the trial, and participated in drafting the manuscript. MST analyzed the data, wrote the results section and provided statistical advice; MB analyzed part of the data; AW assisted in collecting and classifying the data; all authors contributed substantially to the revision of the manuscript. BA takes responsibility for the paper as a whole. All authors read and approved the final manuscript. 


\section{Funding}

No funding was provided for this study.

\section{Availability of data and materials}

The data generated or analysed during this study are included in this published article; if any additional data is requested, please approach the corresponding author (adini@tauex.tau.ac.il); nonetheless, restrictions apply concerning these data, as they were used under specific approval of the Open Clinic of Physicians for Human Rights.

\section{Ethics approval and consent to participate}

The research protocol was approved by the ethics committees of the BenGurion University of the Negev number 20164 from February 2, 2016.

\section{Consent for publication}

Not applicable.

\section{Competing interests}

The authors declare that they have no competing interests.

\section{Author details}

'Emergency management \& disaster medicine department, School of Public Health, Sackler Faculty of Medicine, Tel Aviv University, Tel Aviv, Israel. ${ }^{2}$ National Center for Trauma \& Emergency Medicine Research, the Gertner Institute for Health Policy and Epidemiology, Tel Hashomer, Ramat Gan, Israel. ${ }^{3}$ Medical School for International Health, Ben-Gurion University of the Negev, Beer Sheva, Israel.

Received: 8 June 2019 Accepted: 30 August 2019

Published online: 06 September 2019

\section{References}

1. Staruch RM, Beverly A, Sarfo-Annin JK, Rowbotham S. Calling for the next WHO Global Health initiative: the use of disruptive innovation to meet the health care needs of displaced populations. J Glob Health. 2018;8(1):010303.

2. Abbas M, Aloudat T, Bartolomei J, Carballo M, Durieux-Paillard S, Gabus $\mathrm{L}$, et al. Migrant and refugee populations: a public health and policy perspective on a continuing global crisis. Antimicrob Resist Infect Control. 2018;7(1):113.

3. United Nations high commissioner of refugees (UNHCR). Figures at a glance. Available at: https://www.unhcr.org/figures-at-a-glance.html.

4. Moran EB, Katz MA, Ari OB, Davidovitch N, Zwang O. For what illnesses do asylum seekers and undocumented migrant Workers in Israel Seek Healthcare? An analysis of medical visits at a large urgent Care Clinic for the Uninsured in Tel Aviv. Int J Environ Res Public Health. 2019 Jan;16(2):252.

5. Nakash O, Nagar M, Shoshani A, Lurie I. The association between perceived social support and posttraumatic stress symptoms among Eritrean and Sudanese male asylum seekers in Israel. Int I Cult Mental Health. 2017;10(3):261-75.

6. Raijman R. Asylum seekers and refugees in Israel. Hagira - Israel Journal of Migration. 2017;7:2-6.

7. Nakash O, Langer B, Nagar M, Shoham S, Lurie I, Davidovitch N. Exposure to traumatic experiences among asylum seekers from Eritrea and Sudan during migration to Israel. J Immig Minority Health. 2015;17(4):1280-6.

8. Gebreyesus T, Sultan Z, Ghebrezghiabher HM, Singh N, Tol WA, Winch PJ, et al. Violence en route: Eritrean women asylum-seekers experiences of sexual violence while migrating to Israel. Health Care Women Int. 2019 Feb;2:1-23.

9. Van Reisen M, Rijken C. Sinai trafficking: origin and definition of a new form of human trafficking. Social Inclusion. 2015;3(1):113-24.

10. Bryant RA, Edwards B, Creamer M, O'Donnell M, Forbes D, Felmingham $\mathrm{KL}$, et al. The effect of post-traumatic stress disorder on refugees' parenting and their children's mental health: a cohort study. Lancet Pub Health. 2018;3(5):e249-58

11. Thompson CT, Vidgen A, Roberts NP. Psychological interventions for posttraumatic stress disorder in refugees and asylum seekers: a systematic review and meta-analysis. Clin Psychol Rev. 2018.

12. Berthold SM, Mollica RF, Silove D, Tay AK, Lavelle J, Lindert J. The HTQ-5: revision of the Harvard trauma questionnaire for measuring torture, trauma and DSM-5 PTSD symptoms in refugee populations. Europ J Public Health. 2018;14. https://doi.org/10.1093/eurpub/cky256.
13. Tay AK, Jayasuriya $R$, Jayasuriya $D$, Silove $D$. Assessing the factorial structure and measurement invariance of PTSD by gender and ethnic groups in Sri Lanka: an analysis of the modified Harvard trauma questionnaire (HTQ). J Anxiety Disorders. 2017;47:45-53.

14. Bauhoff S, Göpffarth D. Asylum-seekers in Germany differ from regularly insured in their morbidity, utilizations and costs of care. PLoS One. 2018; 13(5):e0197881.

15. Satinsky E, Fuhr DC, Woodward A, Sondorp E, Roberts B. Mental health care utilisation and access among refugees and asylum seekers in Europe: a systematic review. Health Policy. 2019. https://doi.org/10.1016/ j.healthpol.2019.02.007.

16. Physicians for Human Rights (PHR) Israel. Migrants and Refugees. Available at: https://www.phr.org.il/en/department/migrants-and-refugees/.

17. Open Clinic. Open Clinic for Foreign Workers. Available at: http://stop-abuse. net/Clinic.htm.

18. Nakash O, Nagar M, Shoshani A, Lurie I. The association between acculturation patterns and mental health symptoms among Eritrean and Sudanese asylum seekers in Israel. Cultur Divers Ethnic Minor Psychol. 2015;21(3):468-76.

19. Yaron $\mathrm{H}$, Hashimshony-Yaffe N, Campbell J. "Infiltrators" or refugees? An analysis of Israel's policy towards African asylum-seekers. Int Migr. 2013;51(4):144-57.

20. Bisson Jl. What happened to harmonization of the PTSD diagnosis? The divergence of ICD11 and DSM5. Epidemiol Psychiatr Sci. 2013;22(3):205-7.

21. Akbarzada S, Mackey TK. The Syrian public health and humanitarian crisis: a 'displacement'in global governance? Glob Public Health. 2018;13(7):914-30.

22. Ahmad J, Ahmad A, Ahmad MM, Ahmad N. Mapping displaced populations with reference to social vulnerabilities for post-disaster public health management. Geospat Health. 2017;12(2):576.

23. Poole DN, Hedt-Gauthier B, Liao S, Raymond NA, Bärnighausen T. Major depressive disorder prevalence and risk factors among Syrian asylum seekers in Greece. BMC Public Health. 2018;18(1):908.

24. Tay AK, Rees S, Chen J, et al. Associations of conflict-related trauma and ongoing stressors with the mental health and functioning of west Papuan refugees in Port Moresby, Papua New Guinea (PNG). PLoS One. 2015;10(4):e0125178.

25. Adaku A, Okello J, Lowry B, Kane JC, Alderman S, Musisi S, et al. Mental health and psychosocial support for south Sudanese refugees in northern Uganda: a needs and resource assessment. Confl Health. 2016;10(1):18.

26. Gerdau I, Kizilhan JI, Noll-Hussong M. Posttraumatic stress disorder and related disorders among female Yazidi refugees following Islamic state of Iraq and Syria attacks-a case series and mini-review. Front Psychiatry. 2017;8:282.

27. Wright $A M$, Talia YR, Aldhalimi A, Broadbridge $C L$, Jamil H, Lumley MA, et al. Kidnapping and mental health in iraqi refugees: the role of resilience. J Immigr Minor Health. 2017;19(1):98-107.

28. Harris HP, Zuberi D. Harming refugee and Canadian health: the negative consequences of recent reforms to Canada's interim Federal Health Program. J Int Migration Integration. 2015;16(4):1041-55.

29. Fullerton M. Asylum crisis Italian style: the Dublin regulation collides with European human rights law. Harv Hum Rts J. 2016;29:57.

30. Niedzwiecki MJ, Sharma PJ, Kanzaria HK, McConville S, Hsia RY. Factors associated with emergency department use by patients with and without mental health diagnoses. JAMA Netw Open. 2018;16:e183528.

\section{Publisher's Note}

Springer Nature remains neutral with regard to jurisdictional claims in published maps and institutional affiliations.

Ready to submit your research? Choose BMC and benefit from:

- fast, convenient online submission

- thorough peer review by experienced researchers in your field

- rapid publication on acceptance

- support for research data, including large and complex data types

- gold Open Access which fosters wider collaboration and increased citations

- maximum visibility for your research: over $100 \mathrm{M}$ website views per year

At $\mathrm{BMC}$, research is always in progress.

Learn more biomedcentral.com/submission 